\title{
A False Dichotomy? Mental Illness and Lone-Actor Terrorism
}

\author{
Emily Corner and Paul Gill \\ University College London
}

\begin{abstract}
We test whether significant differences in mental illness exist in a matched sample of lone- and group-based terrorists. We then test whether there are distinct behavioral differences between lone-actor terrorists with and without mental illness. We then stratify our sample across a range of diagnoses and again test whether significant differences exist. We conduct a series of bivariate, multivariate, and multinomial statistical tests using a unique dataset of 119 lone-actor terrorists and a matched sample of group-based terrorists. The odds of a lone-actor terrorist having a mental illness is 13.49 times higher than the odds of a group actor having a mental illness. Lone actors who were mentally ill were 18.07 times more likely to have a spouse or partner who was involved in a wider movement than those without a history of mental illness. Those with a mental illness were more likely to have a proximate upcoming life change, more likely to have been a recent victim of prejudice, and experienced proximate and chronic stress. The results identify behaviors and traits that security agencies can utilize to monitor and prevent lone-actor terrorism events. The correlated behaviors provide an image of how risk can crystalize within the individual offender and that our understanding of lone-actor terrorism should be multivariate in nature.
\end{abstract}

Keywords: terrorism, terrorist, mental health, lone actor, behavior

Attempts to understand the motivation and drives of the individual terrorist have gone through many cycles. Through the 1970 s studies emphasized pathological explanations that posited the compulsion to join a terrorist group, or the vulnerability to recruitment, is inherent in those engaged in militancy. To this end, researchers postulated deviant characteristics of the terrorist personality. Through the 1980s, psychoanalytical approaches concluded that terrorists were not the aggressive psychopaths portrayed to the public, but are hesitant, emotionally damaged youths who are victims of parental rejection that delayed their achievement of adult identity (Victoroff, 2005). Studies that emerged through the late 1990s and early 2000s dismissed these approaches on methodological and empirical grounds (Borum, 2004; Horgan, 2005; Victoroff, 2005).

A consensus soon emerged that group dynamics were key to understanding terrorist motivation. For example, one academic, who in the past championed psychoanalytical interpretations of terrorist motivation, argued that "a clear consensus exists that it is not individual psychology, but group, organizational and social psychology, that provides the greatest analytical power in understanding this complex phenomenon" (Post, 2005, p. 7). This consensus was largely shaped through improved data collection and primary interviews that refuted the above diagnoses. For example, research carried out on the Irish Republican

This article was published Online First August 18, 2014.

Emily Corner and Paul Gill, Department of Security and Crime Science, University College London.

Correspondence concerning this article should be addressed to Paul Gill, Department of Security and Crime Science, University College London, 35 Tavistock Square, London, WC1H 9EZ, United Kingdom. E-mail: paul.gill@ucl.ac.uk
Army (IRA), Northern Ireland loyalists, Hezbollah, German terrorists, the National Liberation Front (FLN), Basque Homeland and Liberty (ETA), Colombian terrorists, global jihadists, and captured Palestinian terrorists has provided evidence that group-based terrorists are psychologically quite normal (Crenshaw, 1981; Ferguson, Burgess, \& Hollywood, 2008; Heskin, 1984; Merari, 1998; Post, Sprinzak, \& Denny, 2003; Rasch, 1979; Reinares, 2007; Sageman, 2005). Typically the population of recruits does not tend to be psychopathological, or for that matter highly uneducated and impoverished because of a selection effect. Organizational elites seek to recruit those most capable of undertaking assigned tasks. Most tasks require an element of secrecy, calibrated violence, and technological know-how. Educated, psychologically healthy, and normal volunteers tend to be preferred for this particular reason. It was argued that those who seek to join but display signs of mental illness may be weeded out in the selection process (Silke, 2003).

The role of mental illness and personality became so completely downplayed that one noted expert recently stated: "we also tried to distinguish terrorists from violent lunatics. Crazies, by definition, could not be terrorists" (Jenkins, 2013, p. 9). In other words, an act of targeted violence is either the action of a rational terrorist or an irrational mentally unstable civilian. Over the space of 40 years of research on terrorist motivation the literature has jumped from one extreme position ("they are all mentally ill") to the exact opposite ("by definition, a terrorist cannot be mentally ill"). This is also reflected in some major criminological research. For example, Gottfredson and Hirschi's control theory views "regular criminals" as impulsive, whereas terrorists need higher levels of control and are implicitly more calculating and, therefore, less likely to be mentally ill. In reality, such distinctions are probably less clear-cut. A 
false dichotomy may exist that categorizes violent individuals as either a rational terrorist or an irrational and unstable individual.

This false dichotomy may be driven by two factors-a misunderstanding of rationality and the focus on group-based actors. Some studies have shown that individuals with mental illness can display rational motivations. For example, Gill, Horgan, and Deckert (2014) illustrate that lone-actor terrorists diagnosed with mental illness frequently display rational motives. Similarly, Borum (2013) highlights a number of terrorists with mental illness who were capable of sophisticated attack planning. In an operational study of assassins, attackers and near-lethal approachers, Fein and Vossekuil (1999), highlight cases of mentally ill individuals planning and executing behaviors as effectively as those lacking diagnosis.

The few existing empirical studies of lone-actor terrorism suggest there is a greater preponderance of mental illness within this category of terrorist actor than that expected within a group-based sample. Fein and Vossekuil (1999) found 61\% of lone assassins had previous contact with mental health services. Hewitt (2003) found $22 \%$ of American "loners" psychologically disturbed. Gill et al. (2014) found $31 \%$ of a sample of lone-actor terrorists to have a history of mental illness. In perhaps the methodologically most sophisticated study, Gruenewald, Chermak, and Freilich (2013), compared a sample of lone extreme right-wing offenders with a sample of group-based extreme right-wing offenders. Loneoffenders had a significantly higher rate of mental illness than group-offenders (40\% vs. $7.6 \%$ ).

These findings suggest a need for revisiting the issue of mental illness as a part of the process for some people becoming involved in terrorism. Mental illness mechanisms remain systematically unexamined, and there may be grounds to pursue a more concrete understanding of how mental illness and psychological processes influence an individual's participation in and trajectory through terrorist behaviors (Gill \& Corner, 2013). The wider criminology literature suggests that much promise exists in utilizing mental illness as a central variable with relation to criminogenic factors. As Anderson (1997) explains, the symbiotic relationship between mental illness and criminal behavior is complex. Comorbidity of mental illness with other behaviors is well documented across the literature and include substance abuse (Todd et al., 2004) and violent and criminal convictions (Anderson, 1997).

Utilizing a unique dataset of 119 lone-actor terrorists and a matched sample of group-based terrorists we first replicate the Gruenewald et al. (2013) study and test whether the significant differences in mental illness also hold true across a sample of actors that contains ideological motivations other than far-right extremism. We then partition our lone-actor sample into two categories (those with and without mental illness diagnoses) and test whether there are distinct characteristic, behavioral, or comorbidity differences between them. Finally, instead of treating mental illness diagnosis as a dichotomy (either you are mentally ill or not), we stratify our sample across a range of diagnoses and again test whether there significant differences appear.

\section{Theory}

Most empirical studies of lone-actor terrorism are largely descriptive, and highlight a number of counterintuitive findings. This article explores whether many of these counterintuitive findings are related to the relatively large preponderance of individuals with mental illness diagnoses. Specifically we test a series of hypotheses related to selection effects, rationality, and stressors.

\section{Mental Illness and Selection Effects}

A number of studies compare lone and group offenders across a wide range of crimes. The results regarding mental illness are mixed. For example, Coid et al. (2013) concluded that gang members demonstrate higher levels of psychiatric morbidity than lone offenders. On the other hand, Bijleveld and Hendriks' (2003) found lone rapists to be significantly more likely to have problematic personality structures than group rapists. Hickle and RoeSepowitz (2010) found lone juvenile arsonists more often came from unstable homes, and experienced school difficulties, behavioral problems, negative emotions, and expressed suicidal thoughts more regularly. Hauffe and Porter (2009) suggest differing pathological processes at play between lone and group offenders.

In terms of terrorism-specific studies Gruenewald et al. (2013) compared far-right group and lone offenders, finding mental illness prevalence differed across offender types (group offender, $7.6 \%$, and lone offender, 40.4\%). Similarly, Hewitt (2003) describes differences in prevalence of mental illness across terrorist group and lone actors $(8.1 \%$ compared with $22 \%)$. These results suggest psychopathological causation differs across terrorist type. This higher preponderance among lone-actor samples may be because of processes that the group-based terrorism literature has long hypothesized. Individuals displaying these traits will not be selected for recruitment. For example, Bueno de Mesquita (2005) utilizes a game theoretic model to demonstrate differences between recruits and sympathisers to terrorist causes. The rationale being that organizations screen recruits to select the most competent to become cadres. Similarly, Horgan (2005) notes that particular individuals may never meet recruitment criteria because of overt psychological characteristics rendering them unsuitable. Spaaij (2010) explains that because of psychological conditions, certain individuals fail to become recruited despite demonstrating willingness, and act independently instead.

Hypothesis 1: Lone-actor terrorists will demonstrate a higher prevalence of mental illness than group-based terrorist actors.

Following the above discussion, we may expect that lone-actor terrorists have previously tried to join a group. Given the temporal and dynamic nature of mental illness, we may also expect that participating group members who later display these traits will be ejected from the group. It is consequently hypothesized:

Hypothesis 2: There will be a difference between mentally ill and nonmentally ill lone actors concerning group entry, participation and removal.

The above hypotheses presuppose that attitudinal affinity to a cause leads individuals to seek recruitment into a group of coideologues. Social movement theorists, however, argue that structural availability is holds greater explanatory power than attitudinal affinity. In other words, predisposition to join a terrorist group is of little use if the would-be-terrorist does not possess the structural opportunities to join. Social movement research illustrates the 
crucial role of structural and network factors in addition to individual attitudinal factors in motivating one toward activism (McAdam, 1986). Looking at existing research on lone actor terrorists and other analogous offender types, a common finding is that a large proportion of these samples are socially isolated individuals who, therefore, may not have the interpersonal connections with a potential recruiter. For example, the Gill et al. (2014) study of lone-actor terrorists characterized $52.9 \%$ of the sample as socially isolated. Meloy, Hempel, Mohandie, Shiva, and Gray (2001) describe $70 \%$ of their subset of adolescent mass murderers as loners and outcasts among peers. Among Fein and Vossekuil's (1999) cohort of assassins, "most" were illustrated as social isolates. Bijeveld and Hendriks (2003) investigation of sex offenders concluded that solo offenders (compared with group) score significantly lower on sociability. When we also consider that other studies have found a link between social isolation and mental illness (Elisha, Castle, \& Hocking, 2006; Thoits, 1983), we hypothesize that:

Hypothesis 3: Mentally ill lone actors are more likely to be characterized as socially isolated than those who are nonmentally ill.

\section{Stressors}

Farrington (1986) presents a general stress model; which hypothesizes that stress is dependent upon the discrepancy between the requirement posed by the stressor stimulus and the coping behaviors utilized from the individual's response capacities. Much of the criminology literature reports that the mentally ill are more susceptible to negative reactions to stressors. For example, Kendler, Karkowski, and Prescott (1999) investigated the impact of stressors on the onset of major depression, concluding there to be a significant causal relationship, and noting individuals predisposed to major depression place themselves into high-risk environments. Roberts, McLaughlin, Conron, and Koenen (2011) cite McLaughlin et al. (2010) who concluded that stress sensitization increases the likelihood of mental illness following exposure to traumatic stressors. Borum et al. (2012) also note that symptoms of mental illness are sometimes not evident, except under continued stress. Situational explanations of crime contend that although longer-term risk factors (in this case stress sensitization) may cause higher predisposition to engage in criminal and violent behaviors, it is the shorter term risk factors (proximate stressors) that act as precursors to the actual commission of the crime. Gill et al.'s (2014) work on lone-actor terrorism supports this. They argue that although it is important to consider distal risk factors, shorter term risk factors are more operationally significant. Of the $32.8 \%$ of lone actors who were impacted by stressors in their sample, $74.3 \%$ experienced those 12 months preceding the attack. This process has also been highlighted in a number of analogous studies. Meloy et al. (2004) found 59\% of their adolescent mass murderer sample experienced a "trigger" event hours or days before the murders. Hickle and Roe-Sepowitz's (2010) research on juvenile arsonists found executors were more likely to "be in crisis," having suffered a major stressor such as the death of a parent, incidence of abuse, pregnancy, or suicide attempt. In 12 of Fein and Vossekuil's (1999) 20 case studies, multiple stressors in the individual's recent lives were present. They concluded that no subject investigated was leading an exemplary life, defined by success in work and family. For almost all of the subjects their attack occurred after a downward spiral. For numerous subjects, one or several stressors appeared to trigger the process that led to the assassination behavior. McCauley et al. (2013) compared school attackers and assassins, finding evidence of stressors in both cohorts (98\% and "nearly half," respectively).

Agnew's (2010) general strain theory of terrorism infers those who act within a group experience collective strains (stressors) seen as undeserved, caused by those with greater perceived power and great in magnitude. Such stressors provoke action. However, Agnew concedes group involvement also aids alleviation of such stressors. Group membership provides outlets for rage and discontent brought forth by strains, inadvertently lessening their adverse effects. Lone actors do not possess the support structure to reduce these stressors, and the above evidence provides explanation for the conclusions of Gill et al. (2014); Gruenewald et al. (2013), and Hewitt (2003).

However, not all lone actors have a history of mental illness, so it is necessary to determine if differences in experience of stressors across actors exist. Despite abundant statistical evidence concerning stressors among both mentally ill and nonmentally ill perpetrators of violence shown above; it is yet to be whether those with mental illness are more likely to encounter stressors and react to them than those who are nonmentally ill. Given the findings related to high-volume crimes, we hypothesize:

Hypothesis 4: Lone actors with a history of mental illness are more likely to have encountered stressors than those with no recorded mental illness.

\section{Irrationality and Violence}

As mentioned previously, recent research demonstrates that the supposed irrationality experienced by the mentally ill is not as debilitating as previously thought (Borum et al., 2012; Gill et al., 2014; Fein \& Vossekuil, 1999). Borum (2013) elucidates: "If the subject . . . been given some diagnostic label, then there is a common tendency to regard that label as a master explanation of the subject's thinking, motives and behavior. It is not." These assertions, however, are largely based on descriptive statistics or illustrative case studies and remain statistically untested.

Furthermore, there is little understanding as to whether these types of actors differ in their ability to successfully carry out a violent attack. The study of the linkages between mental illness and violence has a long history (Teplin, 1984). The Diagnostic and Statistical Manual of Mental Disorders-Fourth Edition-Text Revision (DSM-IV-TR) (American Psychiatric Association, 2000) explains that across psychiatric disorders the risk of violence increases comparable to that of the general population. Ouzir (2013) argues that impulsivity (that is associated with many mental illnesses) and reactive violence largely explain this increased risk of violence. On the other hand, Hiday (1995) and Scott and Resnick (2006) argue those who are mentally ill to be no more dangerous than the general population. These issues have also not been applied in a systematic sense to the types of violence associated with terrorist activity apart from James et al. (2007), who found that mentally ill perpetrators of attacks on European politicians engaged in higher levels of violence. 
Hypothesis 5: Lone actors with a history of mental illness are no more likely to display irrational attack planning behaviors than those with no diagnosis.

Hypothesis 6: Lone actors with a history of mental illness are more violent than those with no diagnosis.

\section{Mental Illness Across a Spectrum}

To expand the terrorist literature it is necessary to expand the dichotomous thinking an individual is either mentally ill or not. Different disorders display different symptoms (DSM-IV-TR, American Psychiatric Association, 2000; International Statistical Classification of Diseases and Related Health Problems-10th revision (ICD-10), World Health Organization, 2010). By viewing actions displayed by a terrorist as either mentally ill or not, the literature becomes stagnant and prevention methods are not as effective as possible. Psychiatric literature often focuses upon levels of violence, demonstrated by numerous studies. Antisocial personality disorder is associated with violence (DSM-IV-TR, American Psychiatric Association, 2000). Fazel and Danesh (2002) describe how this disorder is often seen in prison settings. In a review of 13 investigations concerning violence in mentally ill subjects, Schizophrenia was concluded as being the most reliable indicator, followed by personality disorders and those with organic brain trauma. (Krakowski, Volavka, \& Brizer, 1986). Shaw et al. (2006) provide evidence for differing prevalence rates of mental illnesses across individuals convicted of homicide. Swanson, Holzer, Ganju, and Jono (1990) concluded different disorders present different levels of violence, ranging from phobias (lowest) to drug dependence (highest). This investigation aims to determine if, alongside violence, other variables previously discussed differ across disorders. Therefore, the hypothesis formulated is:

Hypothesis 7: There will be differences in variables across disorders in the cohort.

It is also important to consider comorbidity across psychiatric diagnoses. Saxe et al. (1993) found patients who met criteria for dissociative disorder were significantly more likely to suffer from major depression, PTSD, substance abuse, and borderline personality disorder. Kessler, Chiu, Demler, and Walters (2005) explain; comorbidity of disorders is not as common as being diagnosed with one disorder, but the most severe and pervasive cases are concentrated in the highly comorbid. Singleton et al. (1998) found $76 \%$ of those with a mental illness in the prison population to be diagnosed with two or more disorders. In a more recent epidemiological survey, Elbogen and Johnson (2009) concluded comorbidity of disorders to be a reliable predictor of violence incidence. Abram and Teplin (1991) suggest this pattern is because the complex needs of those with multiple diagnoses make them difficult to place in treatment facilities, and they are arrested as a form of disorder management. Taking into account this evidence it is hypothesized:

Hypothesis 8: There will be differences in variables across comorbid disorders in the cohort.

\section{Data and Method}

The sample includes an extensive codebook from Gill et al.'s (2014) dataset of 119 lone-actor terrorists. Actors were either convicted or died in the commission of their offense in the United States and Europe since 1990. The sample includes violent and nonviolent behaviors carried out by individuals and isolated dyads who either self-radicalized, or radicalized via a larger organization and then carried out acts external to command and control links. Profiles were built using the LexisNexis archive of open source information, scholarly articles, and public record depositories, and the codebook includes 185 variables concerning sociodemographical information, antecedent, event and postevent specific behaviors.

To compare group and lone actors, we also created a sample of group terrorist actors. The observations were sourced from Simcox, Stuart, Ahmed, Murray, and Carlile (2011) and Mother Jones (2013), which contain open source profiles on U.S. and non-U.S. terror-based activities since September 11, 2001. A systematic stratified sampling methodology was utilized to gather the sample of 119 group terrorist actors. The data were matched to the lone actor sample through the country of attack variable (55 U.S. and 64 non-U.S.). This variable was selected to reflect differing psychiatric practices with concerns to law enforcement (James et al., 2007). Group actors were chosen based on confirmed affiliations with organizations, and incarceration not including deportation. Once outliers were excluded there was a sample of 142 non-U.S. group actors and a sample of 286 U.S. group actors. Each actor was assigned a random number (generated using $=$ RAND function in Excel) and using a systematic method $(\mathrm{k}=\mathrm{p} / \mathrm{n})$; in this instance $\mathrm{k}=$ observation, $\mathrm{p}=$ population, and $n=$ sample size. Sampling intervals were generated (2.22 for actions non-U.S. countries and 5.2 for U.S.) and a sample containing 55 U.S. actors and 64 non-U.S. actors was produced (SMART, 2012, p. 9). Using the same extensive search tools as the Gill et al. (2014) study, we coded variables related to mental health issues for each of the chosen group-based actors.

Gill et al.'s (2014) codebook examined mental illness as a dichotomous variable. We created additional variables including the number and name of diagnoses and diagnostic categories. These variables were developed after extensive examination of the available literature on each actor. Available literature was sourced from the Lexis Nexus database, sworn affidavits, indictments, manifestos, warrants, trail proceeding transcripts, trial memorandums, government and expert witness reports, and competency evaluations. The diagnosis name was located in the literature, and reliability and quality of the source was taken into account. For example, one actor was coded as suffering from Asperger's and depression (cited in trial proceedings); however, a newspaper article citing a "friend" (neighbor) as saying they suffered from schizophrenia was discounted, as there was no further evidence for this in any of the other sources concerning said actor. To ascertain the number of diagnoses the same process was carried out. Diagnostic categories were noted either from a confirmed diagnosis in articles, or from a series of symptoms that were cross-referenced with diagnostic material, and given a provisional diagnosis (ICD10, World Health Organization, 2010). For those actors where specific diagnoses were not available and no symptoms provided (e.g., the literature on one actor gave no confirmed diagnoses but confirmed that a mandatory treatment order was given) the outcomes were recorded and it was recorded the actor to have one diagnosis and a diagnostic code of 11 (nonspecific). The ICD-10 diagnostic categories are displayed in Table 1 , and is utilized 
Table 1

ICD-10 Diagnostic Categories

\begin{tabular}{cl}
\hline Diagnostic category & \multicolumn{1}{c}{ Diagnoses or disorders } \\
\hline F00-F09 & Organic \\
F10-F19 & Substance use \\
F20-F29 & Schizophrenia, schizotypal, and delusional \\
F30-F39 & Mood \\
F40-F48 & Neurotic, stress related, and somatoform \\
F50-F59 & Behavioral syndromes associated with \\
& physiological and physical factors \\
F60-F69 & Personality \\
F70-F79 & Intellectual disabilities ("mental retardation") \\
F80-F89 & Disorders of psychological development \\
F90-F98 & Behavioral and emotional, onset in childhood, \\
& and adolescence \\
F99-F99 & Unspecified \\
\hline
\end{tabular}

because of its widespread usage, and is a more valid measure for prevention implications.

\section{Results}

Hypothesis 1: Lone-actor terrorists will demonstrate a higher prevalence of mental illness than group-based terrorist actors.

We first tested whether the rates of mental illness were higher among our sample of lone actors compared with our group-based sample. Whereas the rate of mental illness among the lone-actor sample was $31.9 \%$, the corresponding figure for the group-actor sample was $3.4 \%$. Kolmogorov-Smirnov calculated the percentage of lone actors with mental illness, $\mathrm{D}(119)=0.43, p<.001$ and group actors with mental illness, $\mathrm{D}(119)=0.54, p<.001$ to be significantly non-normal. Levene's test demonstrated that for mental illness, variances were significantly different between lone and group actors, $F(1,236)=284.804, p<.001$. Because the data violated assumptions and are binary categorical, a $\chi^{2}$ test was completed and odds ratio calculated. A $\chi^{2}$ test demonstrated a significant association between offender type (group or lone) and mental illness, $\chi^{2}(1)=33.422, p<.001$. Based on the odds ratio, the odds of a lone actor having a mental illness is 13.49 (95\% confidence interval $[\mathrm{CI}]: 4.630,40)$ times higher than the odds of a group actor having a mental illness.

To compare lone actors with and without a history of mental illness, we followed the procedures of Gruenewald et al. (2013). We first conducted a series of bivariate tests such as $\chi^{2}$ analyses and, where appropriate, Fisher's exact tests. Table 2 outlines the significant differences between these subsets. Variables displaying significant differences were then input into a binary logistic regression to determine the strength of their predictive value in terms of predicting whether the observation had a history of mental illness or not. To determine whether variables have any predictive strength when considering differing and multiple diagnoses, the significant variables from the binary logistic regression were utilized in a multinomial regression.

Hypothesis 2: There will be a difference between mentally ill and nonmentally ill lone actors concerning group entry, participation and removal.

For Hypothesis 2, we compared our lone-actor subsamples across behavioral variables including whether (a) the individual's spouse was part of a wider movement, (b) individual received

Table 2

Observed Percentages for Nonmentally Ill and Mentally Ill Actors

\begin{tabular}{lcc}
\hline & Mentally ill & Nonmentally ill \\
\hline Hypothesis 2 & & \\
Individual's spouse or partner part of wider movement. & $18.4 \%^{* * * *}$ & $1.2 \%$ \\
Command and control links with others. & $7.9 \%$ & $21.0 \%^{*}$ \\
Hypothesis 4 & & \\
Individual's parents divorced. & $31.6 \%^{* * * *}$ & $9.9 \%$ \\
Proximate upcoming life change. & $15.8 \%^{*}$ & $6.2 \%$ \\
In build up to event; individual experienced being target of prejudice. & $28.9 \%^{* *}$ & $11.1 \%$ \\
In build up to event; individual experienced being disrespected. & $28.9 \%^{*}$ & $14.8 \%$ \\
Individual recently under elevated level of stress. & $44.7 \%^{*}$ & $27.2 \%$ \\
Chronic stress in individual's life. & $34.2 \%^{*}$ & $19.8 \%$ \\
Hypothesis 5 & & \\
Recent increase in levels of physical activity. & $21.1 \%^{*}$ & $8.6 \%$ \\
Individual had stockpile of weapons. & $63.2 \%^{* * *}$ & $40.7 \%$ \\
Individual expressed desire to hurt others. & $76.3 \%^{*}$ & $58.0 \%$ \\
Discriminate or nondiscriminate target? & $73.7 \%^{* *}$ & $50.6 \%$ \\
Individual claimed responsibility publicly. & $53.3 \%^{*}$ & $38.3 \%$ \\
Hypothesis 6 & & \\
Individual engaged in violent behavior previous to terrorist event. & $52.6^{* *}$ & $30.9 \%$ \\
Violent attack carried out? & $65.8 \%^{* *}$ & $44.4 \%$ \\
Did the individual kill? & $55.3 \%^{* * *}$ & $24.7 \%$ \\
Did the individual injure? & $52.6 \%^{* * * *}$ & $25.9 \%$ \\
Additional variables & & \\
Single issue inspired individual. & $28.9 \%^{* * *}$ & $12.3 \%$ \\
Born in United States. & $63.2 \%^{* *}$ & $39.5 \%$ \\
Held a Ph.D. & $10.5 \%^{*}$ & $2.5 \%$ \\
\hline
\end{tabular}

${ }^{*} p<.1 .{ }^{* *} p<.05 .{ }^{* * *} p<.01$. 
some form of hands on training from a group, (c) the individual's family or close associates were involved in politically violent groups, (d) the individual interacted face-to-face with members of a wider network, (e) the individual received help in procuring weaponry for the attack, (f) there was evidence of some form of command and control, (g) the individual tried to recruit others, and (h) the individual was ever rejected or ejected from a wider network or group. Some significant associations were found between mental illness and group participation. Those who had a spouse or partner who was involved in a wider movement were 18.07 (95\% CI: $2.134,152.914)$ times more likely to be mentally ill (Fisher's test; $p=.001$ ). Those with command and control links with others were less likely (OR $0.32,95 \%$ CI: $0.880,1.178$ ) to have a mental illness, $\chi^{2}(1)=3.171, p<.1$. All other variables related to this hypothesis presented nonsignificant results.

Hypothesis 3: Mentally ill lone actors are more likely to be characterized as socially isolated than those who are nonmentally ill.

For this hypothesis, we tested a range of behaviors including whether the individual was (a) in a relationship, (b) unemployed, (c) living alone at the time of the event, and (d) characterized as being socially isolated. No variables demonstrated significant associations. Of particular interest here is that the results indicate a lack of association between mental illness and social isolation, $\chi^{2}(1)=0.002, p=.963$. The odds ratio $(0.98,95 \%$ CI: 0.454 , 2.125 ) indicates the null hypothesis should be accepted, and previous nonstatistical conclusions in the literature should be interpreted cautiously.

Hypothesis 4: Lone actors with a history of mental illness are more likely to have encountered stressors than those with no recorded mental illness.

Here, we tested variables including whether the individual had (a) divorced parents, (b) previous military experience, (c) become recently unemployed, (d) a history of substance abuse, (e) experienced a significant work-related stressor, (f) a proximate life goal interrupted, (g) experienced being degraded or disrespected by others, (h) experienced being the target of an act of prejudice, (i) experienced being the victim of physical or verbal assault, (j) recent personal relationship problem, $(\mathrm{k})$ recent financial problems, (l) recently been under an elevated level of stress, (m) experienced long-term sources of stress, and (n) about to experience a proximate upcoming life change.

Some significant associations were found between mental illness and the experience of stressors. Those who have witnessed parental divorce are 4.21 (95\% CI: 1.549, 11.452) times more likely to be diagnosed with a mental illness, $\chi^{2}(1)=8.713, p<$ .01 . Several proximate stressors demonstrated significant associations. Actors with a proximate upcoming life change are $2.85(95 \%$ CI: $0.811,10.014)$ times more likely to have a mental illness (Fisher's test; $p<.1$ ). Those who experience prejudice are 3.26 (95\% CI: $1.216,8.734)$ times more likely to have a mental illness, $\chi^{2}(1)=5.885, p<.05$, and those who experience disrespect are $2.34(95 \%$ CI: $0.923,5.945)$ times more likely to have a mental illness, $\chi^{2}(1)=3.313, p<.1$. Individuals who experience current stress are 2.17 (95\% CI: $0.970,4.858)$ times more likely to be diagnosed with a mental illness, $\chi^{2}(1)=3.627, p<.1$, and individuals who experience chronic stress are 2.13 (95\% CI: 0.889 , 5.018) times more likely to have a mental illness, $\chi^{2}(1)=2.933$, $p<.1$.

Hypothesis 5: Lone actors with a history of mental illness are no more likely to display irrational attack planning behaviors than those with no diagnosis.

Hypothesis 6: Lone actors with a history of mental illness are more violent than those with no diagnosis.

To test issues concerning rationality, we focused on variables related to attack planning, attack commission, and postattack behaviors. These included noting whether the individual (a) became obsessed or fixated with a specific event or phenomena in the attack's build-up, (b) expressed a desire to hurt others, (c) make verbal statements about their intent/beliefs to friends/family/wider audiences, (d) have others aware of their grievance or extremist ideology, (e) have a history of violence before this terrorist incident, (f) consumed propaganda of a wider movement or other lone-actor, (g) sought legitimization from epistemic authority figures for his or her actions, (h) increased levels of physical activity in the build-up to the event, (i) engaged in dry-runs, (j) stockpiled weapons, (k) successfully carried out an attack, (l) targeted discriminately or indiscriminately, (m) used multiple attack methods, (n) killed anybody, (o) injured anybody, or (p) provide a claim of responsibility.

Those with a history of violence are 2.49 (95\% CI: 1.127, 5.497) times more likely to have a mental illness, $\chi^{2}(1)=5.212, p<.05$. Those who increase physical activity levels are 2.82 (95\% CI: $0.939,8.465$ ) times more likely have a mental illness (Fisher's test; $p<.1$ ). Those who stockpile weapons are 2.49 (95\% CI: 1.127 , 5.518) times more likely to be diagnosed with a mental illness, $\chi^{2}(1)=5.208, p>.05$. Individuals who express a desire to hurt others are 2.33 (95\% CI: $0.978,5.555)$ times more likely to have a mental illness, $\chi^{2}(1)=3.750, p<.1$. Those whose target is discriminate are $2.73(95 \% \mathrm{CI}: 1.175,6.348)$ times more likely to be mentally ill, $\chi^{2}(1)=5.649, p<.05$. Actors who carry out a violent attack are $2.4(95 \% \mathrm{CI}: 1.079,5.354)$ times more likely to have a mental illness, $\chi^{2}(1)=4.717, p<.05$. Individuals who kill in an attack are $3.77(95 \% \mathrm{CI}: 1.668,8.510)$ times more likely to be mentally ill, $\chi^{2}(1)=10.705, p=.001$. Actors who injure others in an attack are also 3.18 (95\% CI: $1.415,7.120)$ times more likely to have a mental illness, $\chi^{2}(1)=8.169, p<.01$. Individuals who subsequently claim responsibility publicly are twice as likely $(95 \%$ CI: $0.913,4.350)$ to be mentally ill, $\chi^{2}(1)=3.035, p<.1$.

Finally, we tested a series of other variables to see whether significant differences were apparent among the lone-actor terrorist subgroups. Those who operate within the United States, hold a $\mathrm{Ph} . \mathrm{D}$. and are motivated by single-issue causes are more likely to have a history of mental illness. For obvious reasons, we decided to keep these variables in the logistic regression below. Other variables such as criminal history showed no significant difference.

To determine the probability that mental illness occurs in an individual given a set of predictor variables, a binary logistic regression analysis was carried out. The logistic regression analysis showed that in combination, the independent variables significantly impacted upon mental illness, $\chi^{2}(20)=60.667, p<.001$. The model correctly predicted $83.2 \%$ of responses. A number of 
individual variables were significant predictors of mental illness, as shown in Table 3. Odds of greater than one indicate a positive relationship between the predictor and dependent variable.

These results illustrate a variety of variables with odds ratios suggestive of an impact on mental illness. These variables include having a spouse or partner involved in a wider movement (65.53 [95\% CI: 3.726, 1149.388] times more likely to have a mental illness), making a public claim of responsibility (2.86 [95\% CI: $0.590,19.974]$ times more likely), injuring others in the attack (14.27 [95\% CI: $1.880,108.207]$ times more likely) having previous history of violence $(3.21$ [95\% CI: 0.852, 12.070] times more likely), stockpiling weapons (3.97 [95\% CI: 1.202, 13.130] times more likely), witnessing parental divorce (6.02 [95\% CI: $1.221,29.710]$ times more likely), experiencing an upcoming life change (7.04 [95\% CI: 0.963, 51.445] times more likely), being a victim to an act of prejudice $(4.37$ [95\% CI: 0.808, 23.593] times more likely) and experiencing chronic stress $(3.75$ [0.935, 15.037] times more likely).

Hypothesis 7: There will be differences in variables across disorders in the cohort.

We ran a multinomial logistic regression to determine the probability that different mental illnesses occur in individuals given a set of predictor variables (different manifestations of lone actor behavior). The included diagnostic categories contained a sample of at least three actors. The analysis showed that, in combination, the independent variables significantly impacted upon diagnostic category, $\chi^{2}(45)=110.530, p<.001$. Table 4 depicts an overview of the results.

These results illustrate there to be certain variables that have a significant main effect on diagnostic category (more likely than those who do not perform a behavior). Following the odds ratios, individuals with a spouse or partner involved in terror are 22.2 (95\% CI; 0.704, 1000) times more likely to have a diagnosis of schizophrenia (F20-29) and 250 (95\% CI; 5.495, 13734.377) times more likely to be diagnosed with a mood disorder (F30-39). Individuals who injure in an attack are 11.63 (95\% CI; 2.092, 66.600) times more likely like have schizophrenia and $41.6(95 \%$ CI; $2.488,1000)$ times more likely to have a mood disorder. Those who display prior violence are 5.15 (95\% CI; 1.106, 24.390) times more likely to be schizophrenic. Individuals witness to a parental divorce are $9(95 \% \mathrm{CI} ; 0.872,90.900)$ times more likely to have a mood disorder and 40 (95\% CI; 1.497, 1000) times more likely to have a diagnosis in category F80-89 (developmental disorders). Actors experiencing a proximate life change are $23.26(95 \% \mathrm{CI}$; $2.841,200)$ times more likely to be schizophrenic and $26.32(95 \%$ $\mathrm{CI} ; 0.838,1000)$ times more likely to have a mood disorder. Individuals who experience chronic stress are 4.2 (95\% CI; 0.842, 20.833) times more likely to be diagnosed with schizophrenia and 8.06 (95\% CI; $0.802,83.333)$ times more likely to have a mood disorder.

Hypothesis 8: There will be differences in variables across comorbid disorders in the cohort.

Table 3

Logistic Regression

\begin{tabular}{|c|c|c|c|c|c|}
\hline \multirow[b]{2}{*}{ Variable } & \multirow[b]{2}{*}{$\mathrm{B}(S E)$} & \multirow[b]{2}{*}{ Significant } & \multicolumn{3}{|c|}{$95 \% \mathrm{CI}$ for odds ratio } \\
\hline & & & Lower & $\operatorname{Exp}(\mathrm{B})$ & Upper \\
\hline \multicolumn{6}{|l|}{$\mathrm{H} 2$} \\
\hline Individual's spouse or partner part of wider movement. & $4.182(1.462)$ & $0.004^{* * * *}$ & 3.736 & 65.526 & 1149.388 \\
\hline Command and control links with others. & $-1.163(1.218)$ & 0.339 & 0.029 & 0.312 & 3.399 \\
\hline \multicolumn{6}{|c|}{ 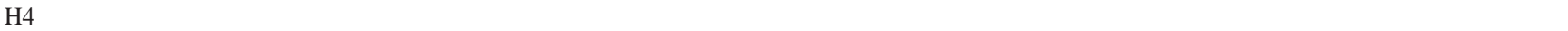 } \\
\hline Individual's parents divorced. & $1.795(0.814)$ & $0.027^{* * *}$ & 1.221 & 6.022 & 29.710 \\
\hline Proximate upcoming life change. & $1.952(1.015)$ & $0.054^{*}$ & 0.963 & 7.040 & 51.445 \\
\hline In build up to event; individual experienced being target of prejudice. & $1.474(0.861)$ & $0.087^{*}$ & 0.808 & 4.366 & 23.593 \\
\hline In build up to event; individual experienced being disrespected. & $0.160(0.810)$ & 0.843 & 0.240 & 1.174 & 5.742 \\
\hline Individual recently under elevated level of stress. & $-0.375(0.747)$ & 0.615 & 0.159 & 0.687 & 2.968 \\
\hline Chronic stress in individual's life. & $1.321(0.709)$ & $0.062^{*}$ & 0.935 & 3.749 & 15.037 \\
\hline \multicolumn{6}{|l|}{ H5 } \\
\hline Recent increase in levels of physical activity. & $-0.396(0.934)$ & 0.671 & 0.108 & 0.673 & 4.195 \\
\hline Individual had stockpile of weapons. & $1.379(0.610)$ & $0.024^{* *}$ & 1.202 & 3.972 & 13.130 \\
\hline Individual expressed desire to hurt others. & $-0.198(0.664)$ & 0.766 & 0.223 & 0.821 & 3.018 \\
\hline Discriminate or nondiscriminate target? & $0.343(0.699)$ & 0.623 & 0.358 & 1.410 & 5.545 \\
\hline Individual claimed responsibility publicly. & $1.050(0.619)$ & $0.090^{*}$ & 0.850 & 2.858 & 9.609 \\
\hline \multicolumn{6}{|l|}{ H6 } \\
\hline Individual engaged in violent behavior previous to terrorist event. & $1.165(0.676)$ & $0.085^{*}$ & 0.852 & 3.207 & 12.070 \\
\hline Violent attack carried out? & $-0.916(1.128)$ & 0.417 & 0.044 & 0.400 & 3.653 \\
\hline Did the individual kill? & $0.092(0.845)$ & 0.914 & 0.209 & 1.096 & 5.739 \\
\hline Did the individual injure? & $2.658(1.034)$ & $0.010^{* *}$ & 1.880 & 14.265 & 108.207 \\
\hline \multicolumn{6}{|l|}{ Additional variables } \\
\hline Single issue inspired individual. & $1.234(0.898)$ & 0.170 & 0.590 & 3.434 & 19.974 \\
\hline Born in the United States. & $0.346(0.699)$ & 0.621 & 0.359 & 1.413 & 5.563 \\
\hline Held a Ph.D. & $1.591(1.381)$ & 0.249 & 0.328 & 4.911 & 73.526 \\
\hline Constant & $-5.267(1.595)$ & 0.001 & & 0.005 & \\
\hline
\end{tabular}

Note. $\mathrm{B}=$ regression coefficient $\operatorname{Exp}(\mathrm{B})=$ odds ratio.

${ }^{*} p<.1 .{ }^{* * *} p<.05 .{ }^{* * * *} p<.01$. 
To establish whether comorbidity of mental disorders affects aspects of terrorist behavior, we ran a multinomial logistic regression. In combination the independent variables significantly impacted upon comorbid disorders, $\chi^{2}(27)=78.679, p<.001$. Table 5 denotes an overview of statistical findings.

These results illustrate there to be certain variables that had a significant main effect on diagnostic category (more likely than those who do not perform the behavior). The odds ratios demonstrate those with a spouse involved in terror are $45.45(95 \% \mathrm{CI}$; $3.984,500)$ times more likely to have one diagnosis, $47.62(95 \%$ CI; $1.221,1000)$ times more likely to have two diagnoses and 500 (95\% CI; 4.695, 57903.880) times more likely to have three or more diagnoses. Individuals who injure are 5.1 (95\% CI; 1.520, 17.241) times more likely to have one diagnoses, 12.5 (95\% CI; $1.314,125)$ times more likely to have two diagnoses, and $50(95 \%$ CI; $1.724,1000)$ times more likely to have three or more diagnoses. Individuals with a history of violence are 2.76 (95\% CI; 0.861 , $8.850)$ times more likely to have one diagnosis. Individuals who stockpile weapons are $3.65(95 \% \mathrm{CI} ; 1.070,12.500)$ times more likely to have one diagnosis, 16.67 (95\% CI; 1.323, 200) times more likely to have two diagnoses, and 11.24 (95\% CI; 0.693 . 166.667) times more likely to have three or more diagnoses. Individuals witness to their parents' divorce are $23.81(95 \% \mathrm{CI}$; $2.825,200)$ times more likely to have two diagnoses and 23.81 $(95 \%$ CI; $1.669,333.333)$ times more likely to have three or more diagnoses. Individuals who experienced prejudice were 4.95 (95\% CI; $1.186,20.833$ ) times more likely to have one diagnosis. Individuals experiencing chronic stress are 14.71 (95\% CI; 1.403 , 142.857 ) times more likely to have two diagnoses. Individuals who experience a proximate life change are 500 (95\% CI; 5.435, 31191.516) times more likely to have three or more diagnoses.

\section{Discussion and Conclusions}

Together the results illustrate the need to readjust our understanding of terrorism and mental illness in a number of ways. First, the results suggest there is a stronger association between mental illness and lone-actor terrorists than mental illness and groupbased terrorists. This reflects the findings of Gruenewald et al.'s (2013) analysis of extreme right-wing offenders who have caused fatalities in the U.S. When we compared our lone actors with a history of mental illness to those without, we further found that those with a history were significantly less likely to have some form of command and control link. This further bolsters the argument that selection effects are at play. Future qualitative research may focus upon the strategies deployed by terrorist recruiters in selecting new cadre. It is also important here to recognize the potential for selectivity bias with regard to using opensource data (Chermak et al., 2010). There is the possibility that reporters are aware of the potential that lone actors are more likely mentally ill, investigate that avenue further and more rigorously and report their findings. As reported above, great care was taken to source information from outside of newspaper reports and we referred to hierarchy of credible sources in the case of conflicting reports. Future research may compare the rates of reporting of mental illness within group actors in cases during the 1970s and 1980 s when the terrorist as mentally ill idea was salient to contemporary cases to check whether such prevailing notions impact upon reporting procedures. 


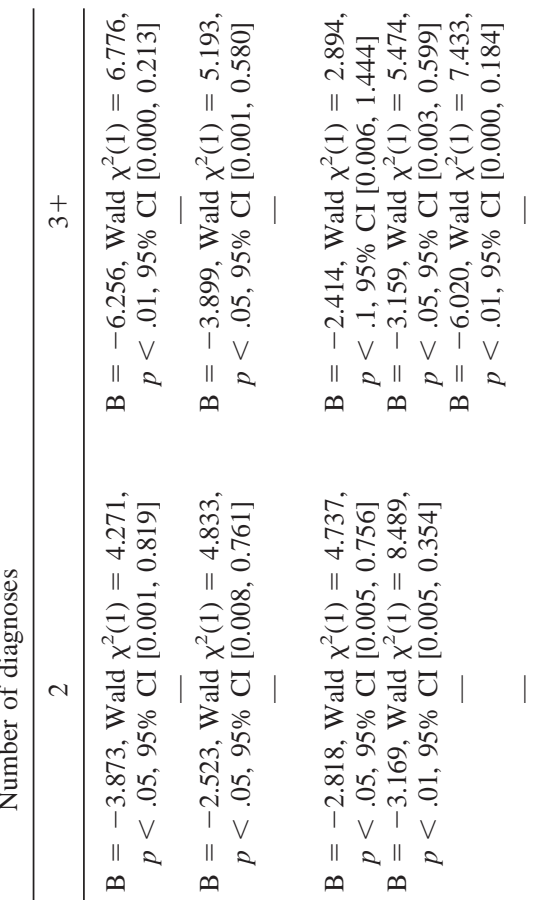

సे

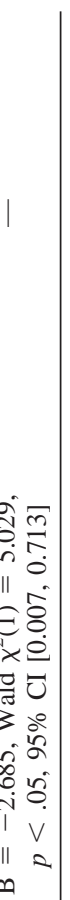

$\|\infty\|-\|$.

च०े

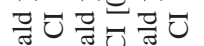

3 잉 3

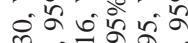

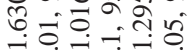

$T \vee T \vee \vee$

$\|=\|=$

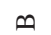

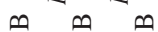

Second, the significant association between mental illness and having a spouse or partner associated with a wider movement suggests those with mental illness may be susceptible to ideological influences in their immediate social environment. Additional case study-based research may identify similarities in ideological leanings and influence between couples.

Third, the most common recurring theme in the literature concerning lone actors is social isolation. This work does not largely deviate from previous conclusions. It demonstrates $52.9 \%$ of lone actors to be socially isolated. This article attempted to bridge the link between the social isolation hypothesis (Thoits, 1983 citing Faris, 1934) and the socially isolative behaviors seen in lone actors. However, the resulting statistics demonstrate those with a history of mental illness are no more likely to have an association with social isolation than those without. This result provides important implications for countering lone actor terrorism, and suggests community services hold the potential to be the most effective discipline in combating this facet of behavior. Further work should investigate community awareness programs concerning identification of potential socially isolated lone actor offenders.

Fourth, we found that lone actors with a history of mental illness are more likely associated with single-issue ideologies than alQaeda inspired or extreme right-wing ideologies. This may also help explain the (initially) counterintuitive finding that those with mental illness are significantly more likely to discriminate between potential targets.

Fifth, those who hold a single-issue ideology are more typically fixated upon a target that they see as wholly responsible for their grievance. For example, Walter Leroy Moody Jr. mailed pipe bombs to specific targets affiliated with criminal courts and Scott Roeder targeted an abortion provider he extensively wrote about online. These behaviors are reflected in certain mental illnesses. Those with mental illness can experience intrusive thought processes, neuroticism and psychotic episodes (American Psychiatric Association, 2000; Link \& Stueve, 1994; World Health Organization, 2010) that cause fixations upon specific "targets" who the individual view as responsible. This finding also follows Clarke and Newman's (2006) work on situational crime prevention. They hypothesize successful attacks to be more likely when opportunities are apparent. Individuals fixating upon singular targets will encounter a great range of opportunities. The above evidence also counters the school of thought which explains irrationality to negatively affect behavior of individuals (Hiday \& Burns, 2010, p. 479), impairing their capability of striking. To provide further statistical evidence, future investigations also ought to consider empirically investigating the targets of attacks. The significant finding that those with a mental illness have an association with claiming responsibility publicly also fits diagnostic criteria of certain mental illnesses (grandiosity, extraversion, delusions, delirium, impulsivity, and attention seeking behaviors; American Psychiatric Association, 2000; World Health Organization, 2010). The finding that those with a mental illness have an association with expressing a desire to hurt others may provide useful directions for prevention efforts. To provide further statistical evidence, it is advised that future investigation should consider diagnostic criteria and links with irrational behaviors demonstrated by mentally ill lone actors.

Sixth, despite previous research showing definitive associations between individual's with mental illness and crime (Anderson, 
1997; Holcom \& Ahr, 1988; Singleton et al., 1998; Teplin, 1984), there were no significant associations found between mental illness and prior criminal behavior. Those with a history of mental illness are no more likely to have a criminal history that those with no history. However, because of the type of data analyzed, it was not possible to discern dates for previous criminal convictions and any psychiatric diagnoses. This could have helped determine whether the terrorist act immediately followed the onset of a disorder. Further investigations should complete such analyses, to definitively conclude whether those with a mental illness are statistically more likely to possess criminal convictions. Although those with a history of mental illness are not more likely to have a prior criminal conviction, the cohort did have a strong statistical link with prior violent behaviors. These results support the preceding literature that those with a mental illness are more likely to be violent. It is suggested that future investigations should consider an actor's history of violence and examine what constitutes violent behavior and its link to criminal convictions.

Seventh, the statistical analyses demonstrated significant associations between mental illness and stressors. The stressor that remained most highly significant across both bivariate and multivariate tests was if the individual's parents were divorced. It is also possible to view divorce as a control variable and a proxy for social integration or lower levels of individual attachment and involvement. On a similar note, studies of far-right fatal violence in the U.S. show that these offenders are more likely to live in counties with higher divorce rates at the time of their offense. To expand on this investigation, further research should test the timescale of stressor variables and the impact upon mental illness onset. Only a small proportion of all stressor variables analyzed showed a significant association with mental illness, aiding professionals when examining patients, as it provides direction for possible intervention.

Eighth, $45 \%$ of the significant variables identified in the bivariate analyses were also significant in the logistic regression analyses. These variables provide direction for mental health professionals, as they should consider liaising with security professionals concerning patients displaying such variables.

Ninth, the first multinomial regression analysis demonstrated certain variables significantly impact upon certain mental illness diagnoses (despite the low number of individuals in each category). Schizophrenia and associated disorders is the only diagnostic group to be significantly associated with previous violence and this supports past research (Krakowski et al., 1986; Shaw et al., 2006). Mood disorders demonstrate their susceptibility to stressors. Those who had divorced parents were significantly more likely to have psychological development disorders (in this cohort, autism). This reflect the stress of raising a child with such a disorder (Higgins, Bailey, \& Pearce, 2005). Negative statistics (though not significant) were found concerning stress related disorders and violent behavior (supporting Swanson et al., 1990). Negative associations were also found between personality disorders and autism and having a spouse or partner related to a terror movement, which may be indicative of not having a spouse because of the detrimental nature of these disorders. These results support previous research. Future work may investigate a larger cohort of diagnoses listed by the $I C D-10$ to confirm and expand upon these findings.
Tenth, the significant variables in the multinomial regression concerning comorbidity of disorders do not present a strong case for rejecting the null hypothesis. Most significant variables were found to be so across all categories. Individual's with one diagnosis were, however, more likely to be violent before the event, contradicting previous evidence (Swanson et al., 1990). The previous multinomial regression also demonstrated Schizophrenic individuals to display the same behavior. In the current cohort it is possible those diagnosed with Schizophrenia had no comorbid diagnoses, resulting in the above finding. Individuals with dualdiagnoses were significantly connected to chronic stress. This finding reflects the previous multinomial regression. Those with mood disorders were also significantly more likely to experience this variable, and of those with a mood disorder in this cohort $66 \%$ had comorbid diagnoses, which may have skewed resulting significant values. The significant finding that those with three or more disorders were more likely to have a proximate upcoming life change should be investigated further, because of its potential function for prevention policies. The cohort size of this regression has limited the significant findings. It is also a preliminary test. Further investigation should expand upon comorbidity and particularly different combinations of comorbid disorders to identify any behaviors useful for mental health professionals. Because mental disorders often share symptoms, further research may also focus upon analyzing symptoms of mental illness rather than the diagnoses themselves (Douglas, Guy, \& Hart, 2009). Unfortunately, this was not possible in this article because of constraints in the available data. However, both authors are currently working alongside colleagues with the United Kingdom's North West Counter Terrorism Unit under Project Regulus to consider both differential diagnosis and symptoms as risk factors of violence in a sample of lone domestic extremists.

Finally, the findings of this investigation provide evidence those lone actors with a history of mental illness are also more likely to engage in certain antecedent events and behaviors that security and policing agencies can utilize to monitor and prevent further developments in attack plotting. In essence, the correlated behaviors provide an image of how risk can crystalize within the individual offender and that our understanding of lone-actor terrorism should be multivariate in nature. The findings presented in this article support James et al. (2007) and Chermak, Freilich, and Simone (2010), who emphasize the need for cooperation between agencies and widespread sharing of information. The empirical evidence suggests mental health professionals may have a role in preventing lone-actor terrorist attacks. If mental health professionals were aware of these findings then screening processes can be carried out by security agencies on patients that present similar antecedents and behaviors in medical evaluations. Examples of multidisciplinary cohesion concerning criminal offenses include the MultiAgency Public Protection Arrangements (MAPPA) and the Fixated Threat Assessment Centre (FTAC). MAPPA involves multiple agencies (including mental health professionals, probation service, police forces, and the HM prison service) who are tasked with managing offenders, and focuses upon a range of offenders (Ministry of Justice, 2012). FTAC is an initiative aiming to protect politicians, the British Royal Family, and other public figures from fixated individuals, by incorporating input from the department of health and the metropolitan police (Fixated Research Group, 2013). MAPPA focuses upon offenders after con- 
viction and release, whereas FTAC assesses potential threats and aims to provide psychiatric services to offenders as a prevention mechanism. We argue that data-driven analyses such as this article can help provide an empirical knowledge base from which organizations like FTAC and MAPPA can make more informed decisions concerning risk and capability.

\section{References}

Abram, K. M., \& Teplin, L. A. (1991). Co-occurring disorders among mentally ill jail detainees: Implications for public policy. American Psychologist, 46, 1036-1045. doi:10.1037//0003-066X.46.10.1036

Agnew, R. (2010). A general strain theory of terrorism. Theoretical Criminology, 14, 131-153.

American Psychiatric Association. (2000). Diagnostic and statistical manual of mental disorders (4th ed., text rev.). Washington, DC: American Psychiatric Association.

Anderson, M. (1997). Mental illness and criminal behaviour: A literature review. Journal of Psychiatric and Mental Health Nursing, 4, 243-250. doi:10.1046/j.1365-2850.1997.00061.x

Bijleveld, C., \& Hendriks, J. (2003). Juvenile sex offenders: Differences between group and solo offenders. Psychology, Crime \& Law, 9, 237 245. doi:10.1080/1068316021000030568

Borum, R. (2004). Psychology of terrorism. Tampa: University of South Florida.

Borum, R. (2013). Informing lone-offender investigations. Criminology \& Public Policy, 12, 103-112. doi:10.1111/1745-9133.12016

Borum, R., Fein, R., \& Vossekuil, B. (2012). A dimensional approach to analyzing lone offender terrorism. Aggression and Violent Behaviour, 17, 389-396. doi:10.1016/j.avb.2012.04.003

Bueno de Mesquita, E. (2005). The quality of terror. American Journal of Political Science, 49, 515-530. doi:10.1111/j.1540-5907.2005.00139.x

Chermak, S. M., Freilich, J. D., \& Simone, J., Jr. (2010). Surveying American state police agencies about lone wolves, far-right criminality and far-right and Islamic Jihadist criminal collaboration. Studies in Conflict \& Terrorism, 33, 1019-1041. doi:10.1080/1057610X.2010 .514698

Clarke, R. V., \& Newman, G. R. (2006). Outsmarting the terrorists. Westport, CT: Praeger Security International, Greenwood Publishing Group.

Coid, J. W., Ullrich, S., Keers, R., Bebbington, P., Destavola, B. L., Kallis, C., . . Donnelly, P. (2013). Gang membership, violence, and psychiatric morbidity. American Journal of Psychiatry, 170, 985-993. doi:10.1176/ appi.ajp.2013.12091188

Crenshaw, M. (1981). The causes of terrorism. Comparative Politics, 13, 379-399. doi: $10.2307 / 421717$

Douglas, K. S., Guy, L. S., \& Hart, S. D. (2009). Psychosis as a risk factor for violence to others: A meta-analysis. Psychological Bulletin, 135, 679-706. doi:10.1037/a0016311

Elbogen, E. B., \& Johnson, S. C. (2009). The intricate link between violence and mental disorder: Results from the national epidemiologic survey on alcohol and related conditions. Archives of General Psychiatry, 66, 152-161. doi:10.1001/archgenpsychiatry.2008.537

Elisha, D., Castle, D., \& Hocking, B. (2006). Reducing social isolation in people with mental illness: The role of the psychiatrist. Australasian Psychiatry, 14, 281-284. doi:10.1080/j.1440-1665.2006.02287.x

Farrington, K. (1986). The application of stress theory to the study of family violence: Principles, problems, and prospects. Journal of Family Violence, 1, 131-147. doi:10.1007/BF00977249

Fazel, S., \& Danesh, J. (2002). Serious mental disorder in 23000 prisoners: A systematic review of 62 surveys. The Lancet, 359, 545-550. doi: 10.1016/S0140-6736(02)07740-1

Fein, R. A., \& Vossekuil, B. (1999). Assassination in the United States: An operational study of recent assassins, attackers, and near-lethal ap- proachers. Journal of Forensic Sciences, 44, 321-333. Retrieved from http://www.secretservice.gov/ntac/ntac_jfs.pdf

Ferguson, N., Burgess, M., \& Hollywood, I. (2008). Crossing the Rubicon: Deciding to become a paramilitary in Northern Ireland. International Journal of Conflict and Violence, 2, 130-137. http://ijcv.org/index.php/ ijcv/article/viewArticle/31

Fixated Research Group. (2013). Preventing harm and facilitating care. Retrieved from http://www.fixatedthreat.com/

Gill, P., \& Corner, E. (2013). Disaggregating terrorist offenders: Implications for research and practice. Criminology \& Public Policy, 12, 93 101. doi:10.1111/1745-9133.12015

Gill, P., Horgan, J., \& Deckert, P. (2014). Bombing alone: Tracing the motivations and antecedent behaviors of lone-actor terrorists. Journal of Forensic Sciences, 59, 425-435. doi:10.1111/1556-4029.12312

Gruenewald, J., Chermak, S., \& Freilich, J. D. (2013). Distinguishing "loner" attacks from other domestic extremist violence: A comparison of far-right homicide. Incident and offender characteristics. Criminology \& Public Policy, 12, 65-91. doi:10.1111/1745-9133.12009

Hauffe, S., \& Porter, L. (2009). An interpersonal comparison of lone and group rape offences. Psychology, Crime \& Law, 15, 469-491. doi 10.1080/10683160802409339

Heskin, K. (1984). The psychology of terrorism in Ireland. In Y. Alexander \& A. O'Day (Eds.), Terrorism in Ireland (pp. 88-105). New York: St. Martin's.

Hewitt, C. (2003). Understanding terrorism in America. New York, NY: Routledge.

Hickle, K. E., \& Roe-Sepowitz, D. E. (2010). Female juvenile arsonists: An exploratory look at characteristics and solo and group arson offences. Legal and Criminological Psychology, 15, 385-399. doi:10.1348/ 135532509X473913

Hiday, V. A. (1995). The social context of mental illness and violence Journal of Health and Social Behaviour, 36, 122-137. Retrieved from http://www.jstor.org/stable/2137220

Hiday, V. A., \& Burns, P. J. (2010). Mental illness and the criminal justice system. In T. L. Scheid \& T. N. Brown (Eds.), A handbook for the study of mental health: Social contexts, theories and systems (2nd ed., pp. 478-498). Cambridge, England: Cambridge University Press.

Higgins, D. J., Bailey, S. R., \& Pearce, J. C. (2005). Factors associated with functioning style and coping strategies of families with a child with an autism spectrum disorder. Autism, 9, 125-137. doi:10.1177/ 1362361305051403

Holcomb, W. R., \& Ahr, P. R. (1988). Arrest rates among young adult psychiatric patients treated in inpatient and outpatient settings. Hospital and Community Psychiatry, 39, 52-57.

Horgan, J. (2005). The psychology of terrorism. London, England: Routledge.

James, D. V., Mullen, P. E., Meloy, J. R., Pathé, M. T., Farnham, F. R., Preston, L., \& Darnley, B. (2007). The role of mental disorder in attacks on European politicians 1990-2004. Acta Psychiatrica Scandinavica, 116, 334-344. doi:10.1111/j.1600-0447.2007.01077.x

Jenkins, B. M. (2013). Foreward. In J. D. Simon (Ed.), Lone wolf terrorism: Understanding the growing threat (pp. 7-11). New York, NY: Prometheus Books.

Kendler, K. S., Karkowski, L. M., \& Prescott, C. A. (1999). Causal relationship between stressful life events and the onset of major depression. American Journal of Psychiatry, 156, 837-841. Retrieved from http://journals.psychiatryonline.org/article.aspx ?articleid $=173488$

Kessler, R. C., Chiu, W. T., Demler, O., \& Walters, E. E. (2005). Prevalence, severity and comorbidity of 12 -month $D S M-I V$ disorders in the national comorbidity survey replication. Archives of General Psychiatry, 62, 617-709. Retrieved from http://apsychoserver.psych.arizona.edu/ JJBAReprints/PSYC621/Kessler\%20et\%20al\%20Arch\%20Gen\%20 Psych\%202005b.pdf 
Krakowski, M., Volavka, J., \& Brizer, D. (1986). Psychopathology and violence: A review of literature. Comprehensive Psychiatry, 27, 131148. doi:10.1016/0010-440X(86)90022-2

Link, B. G., \& Stueve, A. (1994). Psychotic symptoms and the violent/ illegal behavior of mental patients compared to community controls. In J. Monahan \& H. J. Steadman (Eds.), Violence and mental disorder: Developments in risk assessment (pp. 137-160). Chicago, IL: University of Chicago Press.

McAdam, D. (1986). Recruitment to high-risk activism: The case of Freedom Summer. American Journal of Sociology, 92, 64-90. Retrieved from http://www.jstor.org/stable/2779717

McCauley, C., Moskalenko, S., \& Van Son, B. (2013). Characteristics of lone-wolf violent offenders: A comparison of assassins and school attackers. Perspectives on Terrorism, 7, 4-24. Retrieved from http:// www.terrorismanalysts.com/pt/index.php/pot/article/view/240

Meloy, J. R., Hempel, A. G., Gray, T., Mohandie, K., Shiva, A., \& Richards, T. C. (2004). A comparative analysis of North American adolescent and adult mass murderers. Behavioural Sciences and the Law, 22, 291-309. doi:10.1002/bsl.586

Meloy, J. R., Hempel, A. G., Mohandie, K., Shiva, A. A., \& Gray, T. (2001). Offender and offense characteristics of a nonrandom sample of adolescent mass murderers. Journal of the American Academy of Child \& Adolescent Psychiatry, 40, 719-728. doi:10.1097/00004583200106000-00018

Merari, A. (1990). The readiness to kill and die: Suicidal terrorism in the Middle East. In W. Reich (Ed.), Origins of terrorism (p. 192). Washington, DC: Woodrow Wilson Center Press.

Ministry of Justice. (2012). MAPPA guidance: Version 4. Retrieved from http:// www.justice.gov.uk/downloads/offenders/mappa/mappa-guidance-2012-part1 .pdf

Mother Jones. (2013). Profiles in terror. Retrieved from http://www .motherjones.com/fbi-terrorist

Ouzir, M. (2013). Impulsivity in schizophrenia: A comprehensive update. Aggression and Violent Behavior, 18, 247-254. doi:10.1016/j.avb.2012 .11 .014

Post, J. M. (2005). Psychology. In P. R. Neumann (Ed.), Addressing the causes of terrorism: The Club de Madrid series of democracy and terrorism (Vol. 1, pp. 7-12). Madrid, Spain: Club de Madrid.

Post, J., Sprinzak, E., \& Denny, L. (2003). The terrorists in their own words: Interviews with 35 incarcerated Middle Eastern terrorists. Terrorism and political Violence, 15, 171-184. doi:10.1080/ 09546550312331293007

Rasch, W. (1979). Psychological dimensions of political terrorism in the Federal Republic of Germany. International Journal of Law and Psychiatry, 2, 79-85. doi:10.1016/0160-2527(79)90031-1

Reinares, F. (2004). Who are the terrorists? Analyzing changes in sociological profile among members of ETA. Studies in Conflict and Terrorism, 27, 465-488. doi:10.1080/10576100490519741

Roberts, A. L., McLaughlin, K. A., Conron, K. J., \& Koenen, K. C. (2011). Adulthood stressors, history of childhood adversity, and risk of perpetration of intimate partner violence. American Journal of Preventive Medicine, 40, 128-138. doi:10.1016/j.amepre.2010.10.016

Sageman, M. (2005). Understanding terror networks. Philadelphia: University of Pennsylvania Press.

Saxe, G. N., van der Kolk, B. A., Berkowitz, R., Chinman, G., Hall, K., Lieberg, G., \& Schwartz, J. (1993). Dissociative disorders in psychiatric inpatients. American Journal of Psychiatry, 150, 1037-1042. Retrieved from http://ajp.psychiatryonline.org/article.aspx?articleID $=169610$

Scott, C. L., \& Resnick, P. J. (2006). Violence risk assessment in persons with mental illness. Aggression and Violent Behavior, 11, 598-611. doi:10.1016/j.avb.2005.12.003

Shaw, J., Hunt, I. M., Flynn, S., Meehan, J., Robinson, J., Bickley, H., . . Appleby, L. (2006). Rates of mental disorder in people convicted of homicide: National clinical survey. British Journal of Psychiatry, 188, 143-147. doi:10.1192/bjp.188.2.143

Silke, A. (2003). Becoming a terrorist. In A. Silke (Ed.), Terrorists, victims and society: Psychological perspectives on terrorism and its consequences. Chichester, England: Wiley.

Simcox, R., Stuart, H., Ahmed, H., Murray, D., \& Carlile, A. (2011). Islamist terrorism: The British connections. London, England: Henry Jackson Society.

Singleton, N., Meltzer, H., \& Gatward, R. (1998). Psychiatric morbidity among prisoners: Summary report. Government Statistical Service. Retrieved from Office for National Statistics website: http://www.ons.gov .uk/ons/rel/psychiatric-morbidity/psychiatric-morbidity-among-prisoners/ psychiatric-morbidity-among-prisoners-summary-report/index.html

SMART. (2012). Sampling methods and sample size calculation for the SMART methodology. Retrieved from Humanitarian Response website https://assessments.humanitarianresponse.info/document/samplingmethods-and-sample-size-calculation-smart-methodology

Spaaij, R. (2010). The enigma of lone wolf terrorism: An assessment. Studies in Conflict \& Terrorism, 33, 854-870. doi:10.1080/1057610X .2010 .501426

Swanson, J., Holzer, C., Ganju, V. K., \& Jono, R. T. (1990). Violence and psychiatric disorder in the community: Evidence from the epidemiologic catchment area surveys. Hospital \& Community Psychiatry, 41, 761770. Retrieved from http://ps.psychiatryonline.org/article.aspx? articleID $=74352$

Teplin, L. A. (1984). Criminalizing mental disorder: The comparative arrest rate of the mentally ill. American Psychologist, 39, 794-803. doi:10.1037/0003-066X.39.7.794

Thoits, P. A. (1983). Multiple identities and psychological well-being: A reformulation and test of the social isolation hypothesis. American Sociological Review, 48, 174-187. Retrieved from http://www.jstor.org/ stable $/ 2095103$ ? seq $=1 \&$ uid $=3738032 \&$ uid $=2 \&$ uid $=4 \&$ sid $=21104017$ 464783

Todd, J., Green, G., Harrison, M., Ikuesan, B. A., Self, C., Pevalin, D. J., \& Baldacchino, A. (2004). Social exclusion in clients with comorbid mental health and substance misuse problems. Social psychiatry and psychiatric epidemiology, 39, 581-587. doi:10.1007/s00127-004-0790-0

Victoroff, J. (2005). The mind of the terrorist: A review and critique of psychological approaches. The Journal of Conflict Resolution, 49, 3-42. doi: $10.1177 / 0022002704272040$

World Health Organization. (2010). ICD-10: International statistical classification of diseases and related health problems (10th review). Retrieved from http://www.who.int/classifications/icd/en/

Received January 27, 2014 Revision received June 17, 2014 Accepted June 19, 2014 